\title{
"Basta olhar para o mapa": cartografia e história ambiental nas disputas pelo rio São Francisco em meados do século XIX
}

DOI: 10.5935/2237-2717.20150004

\section{"Just look at the map": cartography and Environmental History on land disputes of the São Francisco River in the mid-19th century}

Gabriel Pereira de Oliveira

Universidade Federal de Minas Gerais (UFMG)

gabrielperoli@gmail.com

Belo Horizonte

Brasil

Recibido: 17 de mayo de 2015

Aprobado: 16 de agosto de 2015

\section{RESUMO}

Expressão do modo como certos grupos sociais compreendem e se situam no ambiente, os mapas são peças-chave às interações entre seres humanos e natureza. Longe de constituir espelhos neutros de determinada área ou de ocorrer apenas em função de interesses sociais, a atividade de mapear constrói e reproduz ideias acerca do ambiente ao mesmo tempo que expressa e se faz de acordo com aspectos do meio físico. Este artigo analisa as relações entre sociedade, natureza e cartografia com base nas disputas pelo controle do rio São Francisco, no Brasil, durante o século XIX. Nesse conflito por. um curso d'água cheio de peculiaridades e em que os mapas foram recurso crucial, a aproximação dos campos da história ambiental e da história da cartografia possibilita pensar a documentação cartográfica como fonte valiosa à compreensão das tramas entre rio e seres humanos, meio ambiente e poder.

\section{PalaVRas-chaVe}

História ambiental, história da cartografia, rio São Francisco.

\section{ABSTRACT}

Expression of how certain social groups understand and are in the environment, the maps are key to interactions between humans and nature. Far from being neutral mirror certain area or just be a function of corporate interests, the activity of mapping builds and reproduces ideas about the environment at the same time expressed and do according to aspects of the physical environment. This article analyzes the relationship between society, nature and mapping based on disputes over control of the São Francisco River in Brazil during the nineteenth century. In this conflict by a stream full of quirks and where the maps were crucial resource, the approach of the fields of environmental history and the history of cartography enables think the cartographic documentation as a valuable source for understanding the plots between river and humans, environment and power.

\section{KEYWORDS}

Environmental history, history of cartography, São Francisco River. 
Em viagem pelas caatingas ${ }^{1}$ do Norte do Império do Brasil em 1827, o militar Beaurepaire Rohan² surpreendeu-se ao não encontrar vários leitos fluviais que, de acordo com mapas da região, deveriam existir ali. A partir disso, ele se deu conta de que "a palavra rio nem sempre exprime naquelas paragens a ideia de um curso d'água permanente". Apesar da tendência a adquirir dimensões consideráveis durante o período curto e incerto das chuvas, muitos leitos viam ali seus volumes diminuírem bastante nos meses de estiagem até o ponto de desaparecerem em diversos trechos. Para Rohan, esse regime peculiar de variações na oferta hídrica era, sem dúvida, o motivo pelo qual esses caminhos fluviais figuravam equivocadamente nas cartas geográficas até então. ${ }^{3}$

Por sua vez, o naturalista Alfred Wallace ${ }^{4}$ teve sensação similar ao percorrer o Amazonas e alguns de seus tributários entre 1848 e 1852. Porém, o motivo de sua surpresa foi exatamente 0 oposto daquele que incomodou Rohan. Em vez do estio das caatingas, o excesso de água seria o fator decisivo a ocasionar desenhos imprecisos dos leitos fluviais naquela parte do Império. Durante o período do ano caracterizado pelo grande aumento do volume dos rios, vastas extensões de terra no entorno dos cursos ficariam inundadas, formando os chamados "igapós", "um dos aspectos mais peculiares do Amazonas". ${ }^{5}$ Por conta desse fenômeno, o estudioso britânico relatou ter-se deparado muitas vezes com rios onde, a princípio, imaginou que fosse encontrar terra firme.

Naqueles idos do século XIX, a cartografia despontava como instrumento neutro capaz de desvendar a natureza, o meio para observar a superfície terrestre de modo preciso, objetivo e racional. Porém, tingir num mapa elementos como os rios que, durante certo período, ficavam sem uma gota d'água ou que se estendiam por outras terras constituía sério desafio aos cartógrafos. Afinal, como fixar nas cartas geográficas as instabilidades e peculiaridades da natureza?

Longe de ser dado objetivo, puro reflexo de determinada área, a cartografia se delineou das mais diferentes maneiras no decorrer do tempo e em espaços variados. Além de o meio físico, como no caso dos rios, não constituir ente estático à mercê da humanidade, os diversos grupos sociais entenderam, projetaram e interagiram com 0 ambiente de modo sempre singular. Fundamentais à experiência de compreender 0 espaço e situar-se nele, os mapas seriam instrumentos imersos nessas interações entre seres humanos e natureza, dando sentidos específicos a tais enlaces ao mesmo tempo que seriam tecidos a partir deles.

Este artigo aborda as relações entre sociedade, cartografia e natureza a partir da análise de mapas do rio São Francisco, no Brasil, em meados do século XIX. Embora esse curso d'água não tivesse alterações sazonais tão drásticas quanto outros das caatingas ou da Amazônia, seu leito possuía inúmeras particularidades. Além disso, o São Francisco foi o cerne de disputas políticas intensas no Império brasileiro municiadas, em larga medida, por documentos cartográficos. À luz do diálogo entre parâmetros da história ambiental e da história da cartografia, esta reflexão se pauta na compreensão dos mapas como fonte acerca das interações entre rios e sociedade, do entrelace de natureza e poder.

\section{Um rio de mapas}

Em estudo publicado em 1870, o geólogo canadense Charles Hartt 6 observou que nenhum rio no Brasil havia sido tão cuidadosamente estudado e mapeado quanto o São Francisco. ${ }^{7}$ Esse foi um curso d'água de importância estratégica ao Estado imperial brasileiro no decorrer do século XIX e não despertou tamanho interesse por acaso. Ao atravessar Norte e Sul do país por entre províncias de grande peso político e econômico, a exemplo de Minas Gerais, Bahia e Pernambuco, o São Franciscco foi almejado por elites da época como peça-chave para

\footnotetext{
${ }^{1}$ Durante 0 século XIX, a caatinga referia-se à vegetação seca marcante em parte do Norte do Império do Brasil. Hoje, ela denomina o bioma de flora de caráter xerófito presente no semiárido brasileiro.

${ }^{2}$ Henrique de Beaurepaire Rohan (1812-1894) nasceu em Niterói, província do Rio de Janeiro. Bacharelou-se em Ciências Físicas e Matemáticas, fez carreira no exército e assumiu comissões científicas e militares. Foi presidente das províncias da Paraíba do Norte e do Pará, além de Ministro dos Negócios da Guerra.

${ }^{3}$ Ver a este respeito: Rohan, Henrique de B. Considerações acerca dos melhoramentos de que, em relação ás seccas, são susceptiveis algumas provincias do norté do Brasil (Rio de Janeiro: Tipografia do Correio Mercantil, 1860), 7-8.

${ }^{4}$ Alfred Russel Wallace (1823-1913) nasceu em Usk, País de Gales. Notabilizou-se pelos estudos de história natural, especialmente sobre ecologia e evolução das espécies.

${ }^{5}$ Wallace, Alfred R. Viagens pelo Amazonas e rio Negro (Brasília: Senado Federal, Conselho Editorial, 2004), 513-516. Disponível em: «http://www2.senado.leg.br/bdsf/ite m/id/1092». Acesso em: 19 jun. 2015.

${ }^{6}$ Charles Frederick Hartt (1840-1878) nasceu em New Brunswick, Canadá. Formado no Acadia College, Hartt se notabilizou pelos estudos de ciências naturais, especialmente na área de geologia e paleontologia.

${ }^{7}$ Hartt, Charles F. Geology and physical geography of Brazil(Boston: Fields, Osgood, \& Co., 1870), 275. Disponível em: «https://archive.org/details/cihm_03016». Acesso em: 20 abr. 2015
} 
incrementar a viação interna da nação que se formava. Num período de forte expansão do mercado capitalista aquecido pelo crescimento industrial, aproveitar aquele leito como via de transporte moderna mostrou-se crucial não só à demanda de conectar centros produtivos interioranos com o mercado externo, senão também à consolidação do próprio poder estatal. 0 rio havia de ser 0 caminho navegável capaz de fomentar o potencial produtivo, integrar regiões isoladas e disseminar o ideário do progresso e a ordem imperial por distantes rincões do Império. ${ }^{8}$

Nas primeiras décadas oitocentistas, o São Francisco deu a muitos membros do Estado a impressão de que era um curso d'água estável, bastante propício ao engrandecimento nacional. 0 presidente da província de Minas Gerais em 1843, por exemplo, considerou-0 um rio ao dispor do homem moderno, capaz de oferecer-Ihe uma navegação que já estaria "pronta, e só espera pelos vapores". ${ }^{9}$ Porém, no decorrer do século XIX, com a realização de estudos e explorações de reconhecimento do leito com a finalidade de melhor aproveitá-lo, vários engenheiros e viajantes perceberam o quanto 0 rio estava longe de ser mero elemento passivo nas mãos da sociedade. Era preciso levar em consideração suas peculiaridades para usufrui-lo.

Diante do anseio de incrementar as circulações pelo curso d'água, os aspectos fluviais mais notados foram exatamente aqueles que mais dificultaram 0 aproveitamento de seu leito e exigiram esforços para serem superados. ${ }^{10}$ Eram os chamados obstáculos naturais, motivo de constante frustração às idealizações do São Francisco como viá perfeita de deslocamento. 0 grande símbolo desses embaraços foi a cachoeira de Paulo Afonso, queda d'água também conhecida como o "Niágara brasileiro" e que impossibilitava o sonho da navegação franca desde 0 interior até a foz no Oceano Atlântico. ${ }^{11}$

Em busca de usufruir uma via navegável de enorme importância política e econômica como o São Francisco, grupos procedentes de diversas partes do Império propuseram projetos de estradas de ferro e de rodagem, bem como a abertura de canais de navegação. A meta era desviar as locomoções fluviais sobretudo da barreira representada pela cachoeira de Paulo Afonso, de modo a criar caminhos alternativos para ligar 0 vale ao litoral.

\footnotetext{
${ }^{8}$ Ver a este respeito: Brasil, Vanessa M. Rio da Terra. Rio Histórico. Rio Santo. Caminho de Água. Estrada Fluvial. Nilo Brasileiro. Rio da Unidade Nacional. Rio da Integração Regional. Afinal, Quem é você? In Cidades, rios e patrimônio: memórias e identidades beiradeiras, editado por Gercinair S. Gandara, 41-42. Goiânia: Ed. da PUC Goiás, 2010 .

${ }^{9}$ Falla dirigida á Assembléa Legislativa Provincial de Minas-Geraes na abertura da sessão ordinaria do anno de 1843 pelo presidente da provincia, Francisco José de Souza Soares d'Andréa (Ouro-Preto: Typ. do Correio de Minas, 1843), 39. Disponível em: «http://brazil.crl.edu/bsd/bsd/446/» Acesso em: 5 fev. 2014.

${ }^{10}$ Ver a este respeito a noção de conhecimento da natureza por meio do trabalho: WHITE, Richard. The organic machine. the remaking of the Columbia River (New York: Hill and Wang, 1996), 4.

${ }^{11}$ Rebouças, André. Garantia de Juros. estudos para sua applicação ás emprezas de utilidade publica no Brasil (Rio de Janeiro, Typographia Nacional, 1874), 174; Moraes, Eduardo J. de. Navegação Interior do Brasil (Rio de Janeiro: Typographia Universal de Laemmert, 1869), 54; LIAIS, Emmanuel. Le San Francisco au Brésil par M. Liais. Bulletin de la Société de Geógraphie, ( $5^{\mathrm{me}}$ serie, tome XI, 1866), 390-391. Disponível em: «http://gallica.bnf.fr/ark:/12148/bpt6k376885/f389.image.langEN» Acesso em: 19 Jan. 2014.
} 


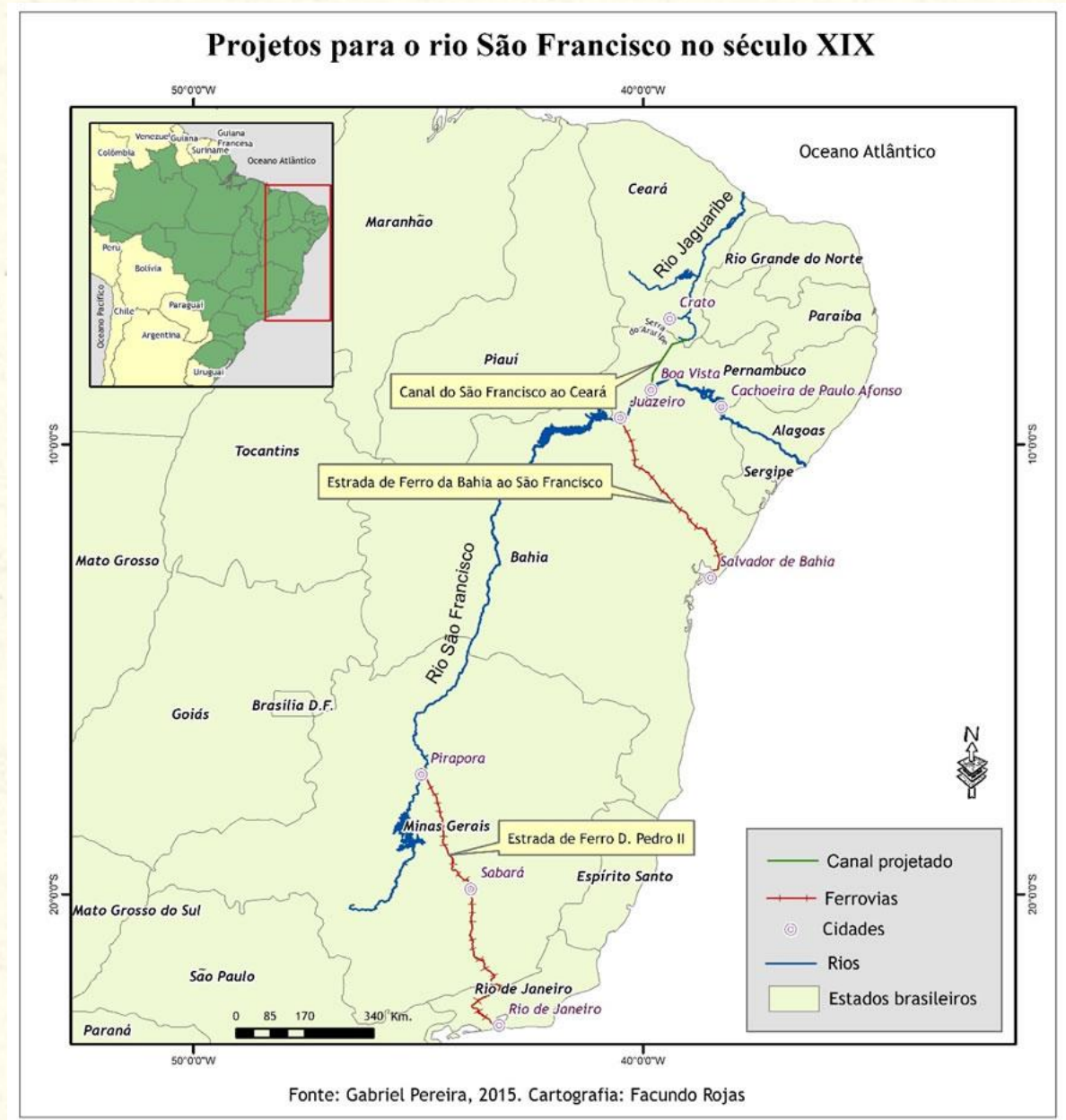

Imagem 1 - Projetos para o rio São Francisco no século XIX.

No entanto, as propostas estiveram bem distantes de ser encaminhadas harmoniosamente. Cada um dos projetos esteve articulado a interesses de diferentes províncias em tornar seus respectivos portos litorâneos a porta privilegiada para entrada e saída do São Francisco. 0 rio se tornava um verdadeiro objeto de disputa, ${ }^{12}$ pleiteado como se fosse um funil. Todos buscavam ser o seu escoadouro, o ponto capaz de concentrar e intermediar toda circulação comercial daquele interior dito ubérrimo com o mar.

Nesses embates pelo controle das comunicações em torno de um rio tão cobiçado, os mapas tiveram importância fundamental. Eles foram primordiais ao processo de elaboração e de busca de legitimação das diversas propostas de transporte. Para entender melhor o papel dessas projeções cartográficas nas disputas pelo São Francisco, é importante primeiramente discutir esse tipo de documentação como fonte histórica articulada, conjuntamente, a projetos de poder e a traços da natureza.

\section{Para além de ilustrações}

Perceber escolhas subjetivas, desvios ou distorções em mapas com fins artísticos ou publicitários parece ser tarefa tranquila. Esses desenhos seriam deliberadamente fictícios, com traços eivados de interferência humana. Sem pautar-se pela precisão cartográfica, tais obras não teriam a pretensa obrigação de expressar 0 ambiente de modo fidedigno. 0 mapa seria apenas uma imagem adaptada e distorcida, feita de acordo com os interesses de quem a desenhou.

\footnotetext{
${ }^{12}$ Ver a este respeito: 0 interior. 0 paiz. Jornal Pedro II. Fortaleza. ñ. 1423. 27 de janeiro de 1855. p. 2; PÁdUA, José Augusto. Um Sopro de Destruição. Pensamento Político e Crítica Ambiental no Brasil Escravista - 1786 - 1888. 2. ed. (Rio de Janeiro: Jorge Zahar Ed., 2004), 28.
} 
Ao contrário, as plantas marcadas pelo rigor da ciência cartográfica não possuiriam qualquer vestígio humano. Elas seriam espelhos puros da superfície territorial, imagens isentas de arbitrariedades. Sob perspectiva fundamentada sobretudo na convicção iluminista em torno da neutralidade do conhecimento científico, ${ }^{13}$ a cartografia constituiria o saber objetivo apto a demonstrar a realidade geográfica. Como suposto retrato do ambiente, os mapas seriam o meio para dar a ver o relevo, cujas coordenadas estariam minuciosamente esquadrinhadas. ${ }^{14}$

Com base nesse enfoque, a cartografia teria grande utilidade também à construção do conhecimento histórico. Pretensa janela a tornar visível a verdade da natureza, um mapa preciso seria o meio por excelência para indicar as localizações e os traços topográficos da superfície. Acima de tudo, a função das imagens cartográficas seria a de revelar 0 ambiente onde os fatos sociais teriam ocorrido e, assim, situar no espaço as experiências analisadas pela historiografia. ${ }^{15}$

Contudo, novas̀ questões e parâmetros metodológicos ganharam força no campo da chamada história da cartografia especialmente a partir das décadas de 1980 e 1990. Em vez de pensar as plantas geográficas simplesmente sob a forma de representações verdadeiras ou falsas de dado ambiente, uma das premissas fundamentais passou a ser a de compreender os mapas como um constructo social. 0 conteúdo e o modo como os aspectos geográficos estariam dispostos em suas linhas não consistiriam em reflexo objetivo da realidade, mas seriam intimamente articulados à sociedade que produziu e se apropriou do mapa das mais variadas formas em dado período e local. ${ }^{16}$

Em vez de ilustração inócua de uma superfície, as cartas geográficas seriam artifícios decisivos para grupos sociais organizarem o território de acordo com seus interesses específicos. No caso das contendas relativas ao São Francisco no século XIX, a cartografia foi elemento vital para o empenho de legitimar determinada conformação do rio e de seu fluxo no espaço nacional como a mais adequada. Nesse sentido, os mapas expressavam uma visão de mundo articulada a demandas sociais ou, como sugerido por Bueno, seriam desenhos a exprimir desígnios, anseios por certos arranjos espaciais. Projetar o território constituiria empenho eminentemente político, fundado em ambições de certos grupos e repleto de efeitos de poder. ${ }^{17}$

Daí a relevância de perceber como os mapas se fazem permeados por escolhas sobre aspectos a incluir ou omitir em seus desenhos. Mesmo quando feitas com o objetivo de desenhar o território do modo mais preciso possível, as plantas geográficas se fariam carregadas de intenções. ${ }^{18}$ Aliás, o maior grau de precisão, como nos casos de imagens feitas com 0 uso de satélites e 0 auxílio da informática, não isentaria a cartografia de arbitrariedades, muito pelo contrário..$^{19} 0$ anseio por medições mais exatas tornou-se fundamental para legitimar os desenhos, funcionando como um autêntico "talismã da autoridade". ${ }^{20}$ Em diálogo com premissa de Chartier de que "as formas produzem sentido", ${ }^{21}$ é importante pensar como os contornos ditos tecnológicos tornam-se capazes de provar determinadas imagens como mais reais do que outras.

Ao fim e ao cabo, o que importa é convencer, afirmar certa leitura do ambiente como a verdadeira: À guisa de um discurso persuasivo, a cartografia se faz uma atividade retórica. Além da formã material, um dos principais artifícios para isso, sobretudo a partir do século XVIII, foi o de tentar afirmar certos arranjos territoriais como

\footnotetext{
${ }^{13}$ Cassirer, Ernst. A filosofia do Iluminismo (Campinas: Ed. Unicamp, 1992), 99.

${ }^{14}$ Harley, John B. La nueva naturaleza de los mapas. Ensayos sobre la historia de la cartografía (México: FCE, 2005), 60-61, 92-93.

${ }^{15}$ Harley, John B. La nueva naturaleza de los mapas. Ensayos sobre la historia de la cartografía (México: FCE, 2005), 59-61.

${ }^{16}$ Ver a este respeito: Crampton, Jeremy W. Maps as social constructions: power, communication, and visualization. Progress in Human Geography 25 (2. 2001.), 236238. Disponível em: «http://phg.sagepub.c om/content/25/2/235.full.pdf+html». Acesso em: 22 jun. 2015; Edney, Matthew H. Putting "Cartography" into the History of Cartography: Arthur H. Robinson, David Woodward, and the Creation of a Discipline. Cartographic perspectives 51. (Spring 2005). Disponível em: «http://www.cartographicper spectives.org/index.php/journal/article/view/cp51-edney/448». Acesso em: 22 jun. 2015; ___. A história da publicação do Mapa da América do Norte de John Mitchell de 1755. Varia Historia 23 (Belo Horizonte. 37. Jan-jun 2007), $31 . \quad$ Disponível em: «http://www.scielo.br/scielo.php?script=sci_arttext\&pid =S010487752007000100003\&lng=pt\&nrm=iso». Acesso em: 9 fev. 2015; HARLEY, John Brian. La nueva naturaleza de los mapas. Ensayos sobre la historia de la cartografía (México: FCE, 2005).

${ }^{17}$ Bueno, Beatriz P. S. Desenho e Desígnio. 0 Brasil dos engenheiros militares (1500-1822). (São Paulo: Editora da Universidade de São Paulo: Fapesp, 2011), 28; Foucault Michel. Microfísica do poder. 26. ed. (Rio de Janeiro: Graal, 2008), 3-4; Harley, John B. La nueva naturaleza de los mapas. Ensayos sobre la historia de la cartografía (México: FCE, 2005), 114, 144, 157-159.

${ }^{18}$ Furtado, Júnia F. Oráculos da geografia iluminista. Dom Luís da Cunha e Jean-Baptiste Bourguignon D'Anville na construção da cartografia do Brasil (Belo Horizonte:

Editora UFMG, 2012), 522. Ver também: Brotton, Jerry. Uma história do mundo em doze mapas (Rio de Janeiro: Zahar, 2014), $22-23$.

${ }^{19}$ Ver a este respeito: «http://www.economist.com/blogs/economist-explains/2014/09/economist-explains-1» Acesso em: 3 nov. 2014.

${ }^{20}$ Harley, John B. La nueva naturaleza de los mapas. Ensayos sobre la historia de la cartografía (México: FCE, 2005), 107.

21 Chartier, Roger. 0 mundo como representação. Estudos avançados 5 (São Paulo. 11. jan-abr. 1991), 178. Disponível em: «http://www.scielo.br/scielo.php?script=sci_arttext\&pid=S0103-4014199100010001 0\&lng=pt\&nrm=is0». Acesso em: 7 jul. 2015.
} 
naturais, algo inerente à natureza. ${ }^{22}$ Nos embates pelo rio São Francisco, por exemplo, esse aspecto foi bastante evidente.

Se o mundo natural, numa perspectiva embasada especialmente no lluminismo, era regido por leis estáveis e inquestionáveis, capazes de conferir autoridade a quem as decifrasse e obedecesse, ${ }^{23}$ a direção correta para os fluxos pelo São Francisco deveria ser indicada pelo meio físico. Pretensamente isenta de ambições sociais, a natureza tornou-se o cerne das disputas. Vários grupos se empenharam em reivindicar e até em provar cientificamente que seus respectivos projetos consistiam no melhor plano, a rota correspondente ao suposto caminho natural para a conexão do rio ao mar.

Ante a noção de que a natureza era fonte de autoridade, a ciência cartográfica constituiria mecanismo fulcral para desvendá-la e utilizá-la como recurso estratégico nos conflitos políticos. A dita superioridade de algumas propostas não seria fruto de arbitrariedades, mas estaria explícita na natureza. E os mapas seriam a prova científica evidente dessa interpretação.

Não por acaso, a expressão "basta olhar para o mapa" foi bastante recorrente naqueles litígios sobre o São Francisco no século XIX. Como sugerido por Said, é de grande importância pensar essas lutas pelo controle territorial como uma questão "complexa e interessante porque não se restringe a soldados e canhões, abrangendo também ideias, formas, imagens e representações". ${ }^{24}$ Se cartografar determinado espaço significava entrar na batalha por ele, ou, como sugerido por Harley, "ser dono do mapa era ser dono da terra", as plantas geográficas atuariam como armas privilegiadas, instrumentos poderosos de conquista e controle. ${ }^{25}$

Assim como na análise de qualquer outro documento, torna-se, então, fundamental considerar as plantas geográficas e suas especificidades em seu contexto, compará-las com outros desenhos e buscar entender seus fundamentos. Ferramentas como o GIS (Geographic Information System) podem ser primordiais nesse sentido. Ao possibilitar a justaposição de dados e mapas variados acerca da mesma área, esses tipos de sistema podem contribuir de modo bastante singular à construção do conhecimento histórico. Como ressaltado por White, a ideia não é encarar esses instrumentos de última geração como retratos perfeitos de um espaço a oferecer respostas prontas à análise histórica, mas pensar alternativas como 0 GIS como meio de pesquisa para compreender e problematizar diferentes relações entre seres humanos e 0 ambiente ao seu redor no decorrer do tempo. ${ }^{26}$

Como diria Benjamin, 0 importante é "escovar" os mapas "a contrapelo". ${ }^{27}$ E, para além das articulações com a sociedade, buscar também outros nós nessa rede a envolver a cartografia pode ser uma experiência bastante interessante. Os desenhos de um ambiente, afinal, estiveram bem distantes de abarcar somente interesses sociais.

\section{Tramas com a natureza}

Apesar de ainda aparecer por vezes na historiografia como simples pano de fundo ou palco das experiências humanas, a natureza e seus elementos como os rios não são meros dados estáticos e passíveis de serem esquadrinhados objetivamente pela cartografia. Mesmo intimamente articulada a demandas sociais, a cartografia não funciona como via de mão única, tecida ao bel-prazer por homens e mulheres guiados por interesses de poder. Como leituras da natureza, os mapas não são elementos externos nem à sociedade nem ao meio físico, mas instrumentos que constroem o ambiente ao mesmo tempo em que se referenciam nele, guiam as relações entre grupos humanos e natureza assim como são delineados por essas mesmas relações. ${ }^{28}$

\footnotetext{
${ }_{22}$ Ver a este respeito: Febvre, Lucien. O Reno. história, mitos e realidades (Rio de Janeiro: Civilização Brasileira, 2000), 73; Latour, Bruno. Ciência em ação. como seguir cientistas e engenheiros sociedade afora. 2. ed. (São Paulo: Ed. Unesp, 2011), 92; Latour, B. Jamais fomos modernos. ensaios de antropologia simétrica (Rio de Janeiro: Ed. 34, 1994), 9-11; Worster, Donald. Rivers of Empire. water, aridity, and the growth of the American West (New York, Toronto: Oxford University Press, 1985$), 138$.

${ }^{23}$ Duarte, Regina H. História \& Natureza (Belo Horizonte: Autêntica, 2005), 79; Sousa Neto, Manoel F. de. Planos para o Império. Os planos de viação do Segundo Reinado (1869-1889). (São Paulo: Alameda, 2012), 124; Williams, Raymond. Ideias sobre a natureza. Cultura e materialismo (São Paulo: Ed. Unesp, 2011), 89-114.

${ }^{24}$ Said, Edward W. Cultura e Imperialismo (São Paulo: Companhia das Letras, 2011), 40.

${ }^{25}$ Bueno, Beatriz P. S. Decifrando mapas: sobre o conceito de "território" e suas vinculações com a cartografia. Anais do Museu Paulista 12 (São Paulo. jan-dez 2004), 230. Disponível em: «http://www.scielo.br/scielo.php?script=sci_arttext\&pid=S0101-47142004000100018\&lng=en\&nrm=iso \&tlng=pt»; Harley, John B. La nueva naturaleza de los mapas. Ensayos sobre la historia de la cartografía (México: FCE, 2005), 104, 181; Said, Edward W. Cultura e Imperialismo (São Paulo: Companhia das Letras, 2011), 125.

${ }_{26}$ White, Richard. What is Spatial History? Stanford University Spatial History Lab: (Stanford, feb. 2010), 4-6. Disponível em: «https://web.stanford.edu/group/spatialhistory/cgi-bin/site/pub.php?id=29». Acesso em: 29 jun. 2015.

${ }^{27}$ Löwy, Michel. Walter Benjamin. Aviso de incêndio - uma leitura das teses "Sobre o conceito de História" (São Paulo: Boitempo, 2005), 70.

${ }^{28}$ Ver a este respeito: Crampton, Jeremy W. Maps as social constructions: power, communication, and visualization. Progress in Human Geography 25 (2. 2001.), 239;

Gallini, Stefania. Problemas de metodos en la historia ambiental de America Latina. Anuario IHES 19 (Buenos Aires: 2004), 2. Disponível em: «http://www.unicen.edu.ar/iehs/files/Problemas\%20de\%20m\%C3\%A9todos\%20en\%20l a\%20histori a\%20ambiental\%20de\%20Am\%C3\%A9rica\%20Latina.pdf». Acesso
} 
Tecidos no infermédio entre características ambientais, demandas sociais, habilidades científicas e disputas políticas, a documentação cartográfica constitui vestígio privilegiado acerca dos elos entre sociedade e meio físico, e não de um ou outro em separado. Assim, os mapas mostram-se materiais valiosos para o campo da história ambiental, que se pauta exatamente na compreensão das interações entre seres humanos e natureza no decorrer do tempo e em diferentes espaços.

Por um lado, estudar plantas cartográficas do rio São Francisco do século XIX significa estudar parte da experiência política do Brasil da época, a distribuição de poder no regime imperial e os processos de construção do Estado brasileiro. ${ }^{29}$ Afinal, os modos pelos quais diferentes indivíduos compreenderam, descreveram e se relacionaram com a natureza estiveram profundamente entrelaçados a valores e demandas específicas de cada um deles, bem como a dinâmicas sociais e jogos políticos da época. 0 rio foi cartografado e sofreu interferências sociais muito de acordo com as experiências humanas a que esteve relacionado historicamente. ${ }^{30}$

Por outro lado, é importante observar ao mesmo tempo como os mapas não se fizeram apenas em função de aspectos sociais, mas também de elementos do meio físico. Nesse sentido, é bastante emblemático como engenheiros e administradores públicos enfatizaram a importância de conhecer os chamados obstáculos da natureza, adaptando suas propostas à coexistência com bancos de areia, pedras, quedas d'água, variações no nível de profundidade do leito e do volume hídrico. Para o estudioso Thomaz Montenegro em 1875, ${ }^{11}$ por exemplo, compreender "o São Francisco e suas circunstâncias" era condição imperiosa para poder aproveitá-lo ${ }^{32}$ Daí a grande relevância de investigar, conforme ressaltado por Jakobsson, como foi preciso que grupos sociais levassem em consideração e muitas vezes se adequassem às sinuosidades do rio, às características do curso das águas. ${ }^{33}$ Afinal, se os mapas fundamentaram certos usos e apropriações do rio, o leito fluvial também foi importante para 0 desenvolvimento tanto das cartas geográficas como das próprias dinâmicas sociais ao condicionar determinados caminhos, oferecer barreiras e exigir a realização por vezes de trabalhos árduos.

Além do grande obstáculo da cachoeira de Paulo Afonso, outro exemplo significativo da exigência de adequação às peculiaridades hídricas foram os regimes sazonais de cheias e vazantes. Embora de forma menos acentuada do que em rios da Amazônia ou das caatingas, as variações no São Francisco também foram consideráveis no decorrer do século XIX. Na estação seca, entre os meses de maio e outubro, a possibilidade de deslocamento em alguns trechos tornava-se incerta ou muito complicada. Muitas vezes, era necessária a presença de pilotos "práticos que abundam nas povoações ribeirinhas", que conheciam o rio como ninguém. ${ }^{34}$ De acordo com 0 engenheiro Fernando Halfeld ${ }^{35}$ nos anos 1850, durante a estação seca, "acontece, às vezes, que [...] embarcações encalham levemente sobre as areias ou coroas que se mudaram de um para outro lugar, ou que de novo se formaram durante as últimas enchentes de cada ano, e cuja posição ainda é desconhecida aos navegantes" ${ }^{36}$ Já na estação das cheias "a dificuldade consiste somente em vencer a correnteza das águas". ${ }^{37}$

A pretensa missão de conhecer objetivamente as leis da natureza com o intuito de dominá-la, impor-Ihe a regularidade e a pragmaticidade científica, colocando-a ao dispor de propósitos humanos mostrou-se bem mais difícil de ocorrer do que se poderia supor inicialmente, com base no ideário iluminista. Diante dos meandros fluviais complicados e instáveis, o senador Fernandes da Cunha ${ }^{38}$ lamentou as dificuldades de projetar "obras

em: 22 abr. 2014; Stewart, Mart A. "William Gerard de Brahm's 1757 Map of South Carolina and Georgia”. Environmental History 16 (jul. 2011), 524; Wood, Denis. Rethinking the power of maps (New York, Guilford Press, 2010), 39-52.

${ }^{29}$ Ver a este respeito: Blackbourn, David. "Time is a violent torrent": Constructing and Reconstructing Rivers in Modern German History. In: Mauch, Christof; Zeller, Thomas (ed.). Rivers in history. perspectives on waterways in Europe and North America (Pittsburgh: University of Pittsburgh Press, 2008), 24.

${ }^{30}$ Ver a este respeito: White, Richard. The organic machine. the remaking of the Columbia River (New York: Hill and Wang, 1996), 37 ; Landscapes: The Cultural Turn in Environmental History. The Historian 66 (n. 3. Fall 2004), 557-564; CIOC, Mark. The Rhine. an eco-biography, 1815-2000 (Seattle: University of Washington Press, 2002), 15.

${ }_{31}$ Thomaz Garcez Paranhos Montenegro nasceu em 1839 na Bahia. Foi bacharel em Direito e atuou como juiz na região do rio São Francisco.

${ }^{32}$ Montenegro, Thomaz G. P. A Provincia e a Navegação do rio São Francisco (Bahia: Imprensa Economica, 1875), 175.

${ }_{33}$ Jakobsson, Eva. Industrialization of rivers: A water system approach to hydropower development. Knowledge, Technology \& Policy 14 (n. 4. Winter 2002), 47;

Ditching from a water system perspective. Draining the Swedish Water Landscape 1200-1900. Water History5 (2013), 350. Ver também a este respeito: CRONON, William. Time and the river flowing. In: Cioc, Mark. The Rhine. an eco-biography, 1815-2000 (Seattle: University of Washington Press, 2002), XII.

34 Deputado Christiano Ottoni. Anais da Câmara dos Deputados. Sessão de 26 de agosto de 1861. p. 289. Disponível em: «http://imagem.camara.gov.br/pesquisa diario basica.asp». Acesso em: 6 mai. 2014.

${ }^{35}$ Heinrich Wilhelm Ferdinand Halfeld (1797-1873) nasceu em Clausthal Zellerfeld, no então Reino de Hannover. Halfeld estudou engenharia na Academia de Minas em sua cidade natal. Mudou-se para o Brasil em 1825 como oficial do exército e ficou conhecido como Henrique Guilherme Fernando Halfeld.

${ }^{36}$ Copia de uma parte do officio dirigido ao Ex.mo Senr. Ministro do Imperio pelo Engenheiro Fernando Halfeld dando afirmações resumidas respeito á exploração do Rio de S. Francisco. (APM). SPPP1 45, CX. 01, doc. 52.

${ }^{37}$ Montenegro, Thomaz G. P. A Provincia e a Navegação do rio São Francisco (Bahia: Imprensa Economica, 1875), 147.

${ }^{38}$ Joaquim Jerônimo Fernandes da Cunha (1827-1903) nasceu em Juazeiro, na Bahia. Bacharelou-se em Ciências Sociais e Jurídicas em 1847. Foi deputado provincial, deputado geral e senador por sua província. 
hidráulicas, em que todos os princípios do cálculo e da ciência respectiva lutam com forças incógnitas e imprevistas, com casos de força maior, que burlam todos os cálculos". ${ }^{39}$

Entretanto, as definições de traços específicos do ambiente como errôneos não eram dados objetivos ou reconhecidos de modo homogêneo pela sociedade da época, mas se fizeram de modo intimamente entrelaçado a experiências sociais. Cada grupo interpretava as características do rio de acordo com seus respectivos interesses. A definição dos pontos até onde o leito do São Francisco seria navegável e de quais trechos deveriam receber obras para melhorar as condições de navegabilidade envolviam não somente traços do curso d'água, mas projetos políticos e econômicos. Muito mais do que apenas reparar supostos erros da natureza, a intenção dos mais diferentes sujeitos em disputa era ter 0 controle do rio e colocá-lo a serviço de suas demandas particulares. ${ }^{40}$

A depender do projeto ao qual estivesse articulado, o mapa trataria determinados aspectos do vale do São Francisco como dignos ou não de constar em suas linhas. Seu desenho levaria em conta os traços fluviais, mas também arranjaria 0 território e conformaria 0 rio no espaço em função de certas demandas sociais. Como sugerido por White em estudo sobre o rio Columbia, o curso d’água não era apenas água correndo pelo leito, mas "uma máquina orgânica, uma criação parcialmente humana, em que cada um dos grupos que reivindicaram o rio criaram a parte que eles reivindicaram" ${ }^{41}$ Conforme sugerido por Lima, ${ }^{42}$ em vez de ser dado fixo, imutável ou homogêneo, "um rio são muitos". A cartografia foi justamente uma das formas de expressão e construção dessas múltiplas percepções de leitos como o São Francisco, de como o rio e sua materialidade foram vividos e fizeram sentido sob os mais variados prismas para diferentes sujeitos, num enlace de natureza e poder. ${ }^{43}$

\section{Batalha de mapas}

Marcados pelo recurso aos mapas, os conflitos pelo controle do rio São Francisco no século XIX constituíram, não raras vezes, uma legítima guerra cartográfica. As plantas relativas àquele vale entre Norte e Sul do Brasil funcionaram como armas de grande relevância a viabilizar o empenho de diferentes grupos em afirmar seus projetos como os melhores e, consequentemente, os que mereceriam a prioridade de recursos do orçamento imperial. A seguir, analisarei mais detidamente como as projeções cartográficas dos planos de estradas de ferro de D. Pedro II e da Bahia, bem como o do canal ao Ceará se delinearam em meio às relações entre sociedade e natureza.

Primeiramente, destaco o mapa elaborado entre 1866 e 1867 (ver imagem 2), de modo muito provável, por John Whitaker. ${ }^{44}$ Contratado pelo governo imperial brasileiro, esse engenheiro foi incumbido de demonstrar e averiguar diferentes possibilidades para ligar a capital do país, o Rio de Janeiro, aos trechos navegáveis do São Francisco por meio da estrada de ferro D. Pedro II. Esse foi um projeto do interesse sobretudo de elites fincadas nas províncias do Rio de Janeiro e de Minas Gerais. Aquela via férrea e o domínio consequente das circulações por um caminho estratégico como o São Francisco seriam cruciais para conformar o tërritório do Império de modo favorável àquelas partes da nação. A grande meta era consolidar a centralização do poder imperial na Corte, fazendo tudo convergir para ali, o centro de gravidade do país.

\footnotetext{
${ }^{39}$ Anais do Senado. Sessão de 10 de maio de 1883. Livro 1. p. 282. Disponível em: < http://www.senado.go v.br/publicacoes/anais/asp/IP_Anaislmperio.asp > . Acesso em: 25 fev. 2014.

${ }^{40}$ White, The organic machine, 31.

${ }^{41}$ No original: "an organic machine, a partial human creation, each of the groups claiming the river has created part of they claim." (tradução minha) WHITE, Richard. The organic machine: the remaking of the Columbia River (New York: Hill and Wang, 1996), 110.

42 Lima, Roberto. Um rio são muitos - de aventura e antropologia no rio São Francisco. Tempo Social, Rev. Sociol. USP 12 (São Paulo, 2, nov. 2000). Ver também: Febvre Lucien. O Reno. história, mitos e realidades (Rio de Janeiro: Civilização Brasileira, 2000), 83.

${ }^{43}$ Down to Earth: Nature, Agency, and Power in History. The American Historical Review 3 (jun. 2002), 800-803.

${ }^{44}$ John Whitaker nasceu nos Estados Unidos e atuou como engenheiro no Império brasileiro.
} 

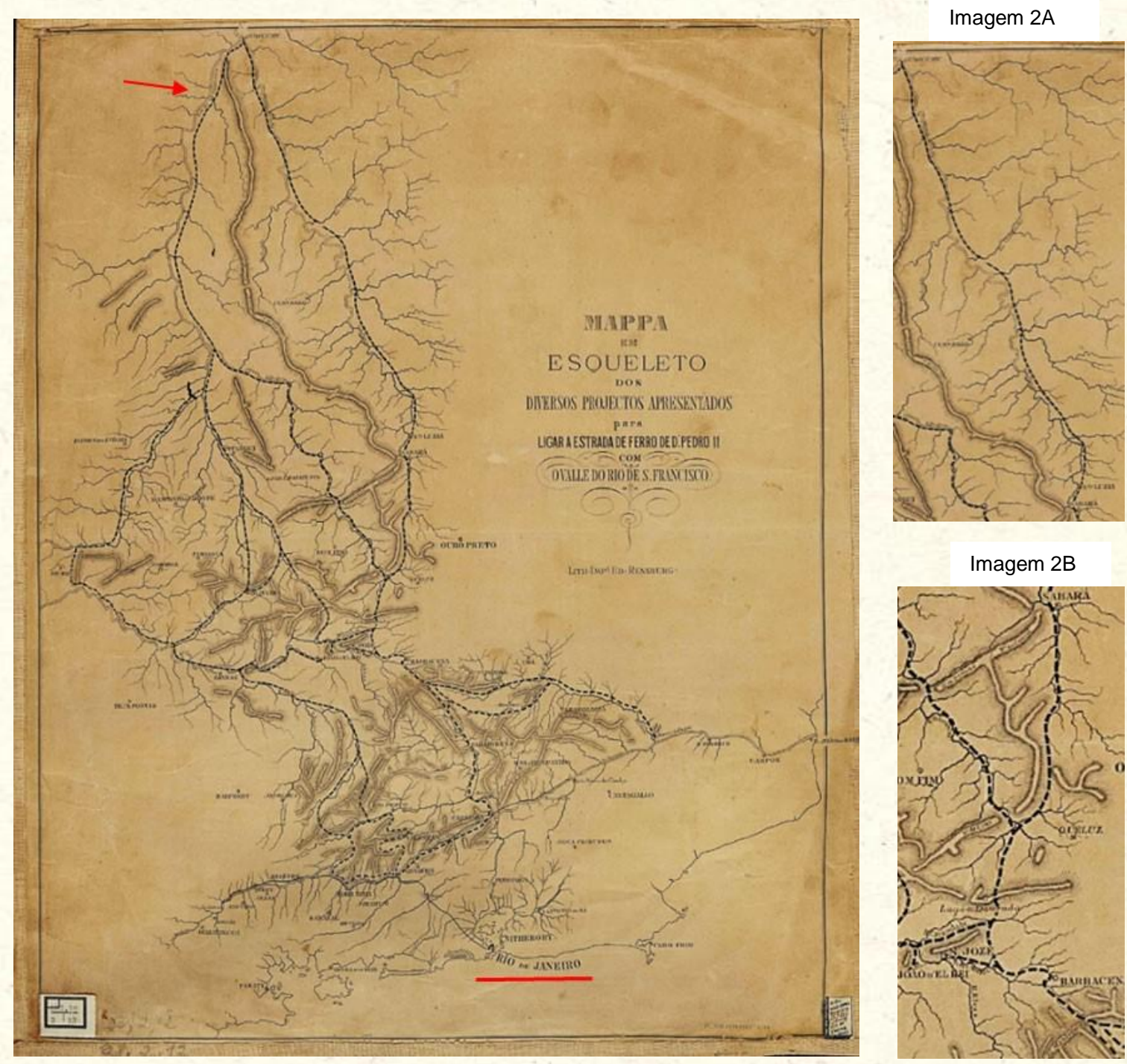

Imagem 2 - BNRJ. Mappa em esqueleto dos diversos projectos apresentados para ligar a estrada de ferro de $\mathrm{d}$. Pedro II com o valle do Rio de S. Francisco. Rio de Janeiro: Lith. Imp. Ed. Rensburg, [s.d.]. 45,5 × 35,3 cm.

Sem entrar em detalhes sobre as projeções concorrentes, Whitaker analisou exclusivamente os "diversos traços propostos fazendo o centro na cidade do Rio de Janeiro". Embora o caminho sugerido pelo engenheiro fosse um tanto sinuoso e exigisse a travessia por algumas montanhas, ele garantiu a ocorrência de terrenos rebaixados e a possibilidade de contornar perfeitamente outras elevações (ver imagem 2B). Feita de acordo com os traços da natureza, tal via seguiria até mesmo o leito de rios da região em alguns trechos (ver imagem $2 \mathrm{~A}$ ). Além disso, esse seria um percurso não apenas viável tecnicamente, mas também marcado pela fartura de seus solos, passando por áreas produtivas capazes de auferir os maiores lucros.

Para Whitaker, o melhor percurso para ligar o São Francisco ao litoral não deveria ser necessariamente 0 mais curto ou direto, mas sim aquele que fosse mais rentável. ${ }^{45} \mathrm{Em}$ vez de ser fruto de escolhas tendenciosas, a natureza era quem supostamente indicaria esse melhor trajeto. E a missão de desvendar qual seria esse caminho natural caberia a um engenheiro, como o próprio Whitaker. Porém, não foi de estranhar que a rota sugerida por

\footnotetext{
${ }^{45}$ Relatorio do chefe da comissão encarregada dos estudos do prolongamento da Estrada de Ferro de D. Pedro II. p. 3-5. In: Anexo M - Relatorio apresentado a Assemblea Geral Legislativa na primeira sessão da Decima Terceira Legislatura pelo Ministro e Secretario de Estado dos Negocios da Agricultura, Commercio e Obras Publicas Manoel Pinto de Souza Dantas. (Rio de Janeiro: Typographia Perseverança, 1867). Disponível em: <http://brazil.crl.edu/bsd/bsd/u1951/>. Acesso em: 17 mar. 2014.
} 
ele, devidamente refèrenciada pelo mapa, fosse bastante favorável aos interesses dos contratantes de seus estudos. A pretensa via mais adequada era justamente aquela conforme ao projeto de centralização do Império no Rio de Janeiro e que passava pelas cercanias de cidades importantes de Minas Gerais, inclusive de sua capital.

No entanto, esse arranjo territorial esteve muito distante de ser a única alternativa pensada para o São Francisco. Muitos outros se apropriaram da cartografia sob prismas peculiares, utilizando-a como embasamento para leituras e projeções do meio físico de acordo com interesses de porções distintas do Império. Um dos principais projetos concorrentes à leitura articulada à Corte procedeu da Bahia, onde elites se empenhavam cada vez mais em conectar o São Francisco ao Oceano Atlântico por meio de uma via férrea até a capital daquela província. Nessa contenda em que os mapas foram uma das principais armas, grupos baianos não prescindiram da cartografia como meio de contestar os projetos contrários e de defender a pretensa superioridade natural e incontestável da Bahia. ${ }^{46}$

Para o senador Fernandes da Cunha, por exemplo, se os mapas eram, de fato, espelhos precisos da natureza geográfica do Império, eles deveriam indicar quais os caminhos mais adequados a serem feitos. Assim, a cartografia não poderia servir para outra função senão a de "convencer que só há uma estrada para o S. Francisco: é a da Bahia". As discussões e incertezas quanto ao melhor percurso seriam completamente desnecessárias: "para que estas coisas? Basta olhar para o mapa", sugeriu Cunha. "A via natural do Rio S. Francisco é da capital da Bahia à cidade do Juazeiro. Deixem-se de obstinação". ${ }^{47}$

A carta geográfica (ver imagem 3) publicada em 1870 pelo engenheiro britânico Hugh Wilson 48 foi instrumento importante aos defensores da via férrea da Bahia. Contratado pelo governo baiano para demonstrar, com 0 devido rigor científico, a superioridade dos planos daquela província, Wilson elencou as principais propostas de estradas de ferro em direção ao São Francisco. Porém, ele também não perdeu a oportunidade proporcionada pela planta geográfica para contestar os projetos concorrentes, especialmente a via férrea de D. Pedro II.

\footnotetext{
${ }^{46}$ Falla recitada na abertura da Assembléa Legislativa da Bahia pelo presidente da provincia, o doutor João Mauricio Wanderley, no 1.0 de março de 1854 . (Bahia, Typ. de Antonio Olavo da França Guerra e Comp., 1854), 29. Disponível em: <http://brazil.crl.edu/bsd/bsd/117/>. Acesso em: 7 abr. 2014.

47 Deputado Fernandes da Cunha. Anais do Senado do Império. Sessão de 16 de setembro de 1879. p. 131; p. 195. Disponível em: < http://www.senado.go v.br/publicacoes/anais/asp/IP_Anaislmperio.asp>. Acesso em: 25 fev. 2014.

${ }^{48}$ Hugh Wilson nasceu na Inglaterra e foi importante acionista do ramo ferroviário na província da Bahia.
} 

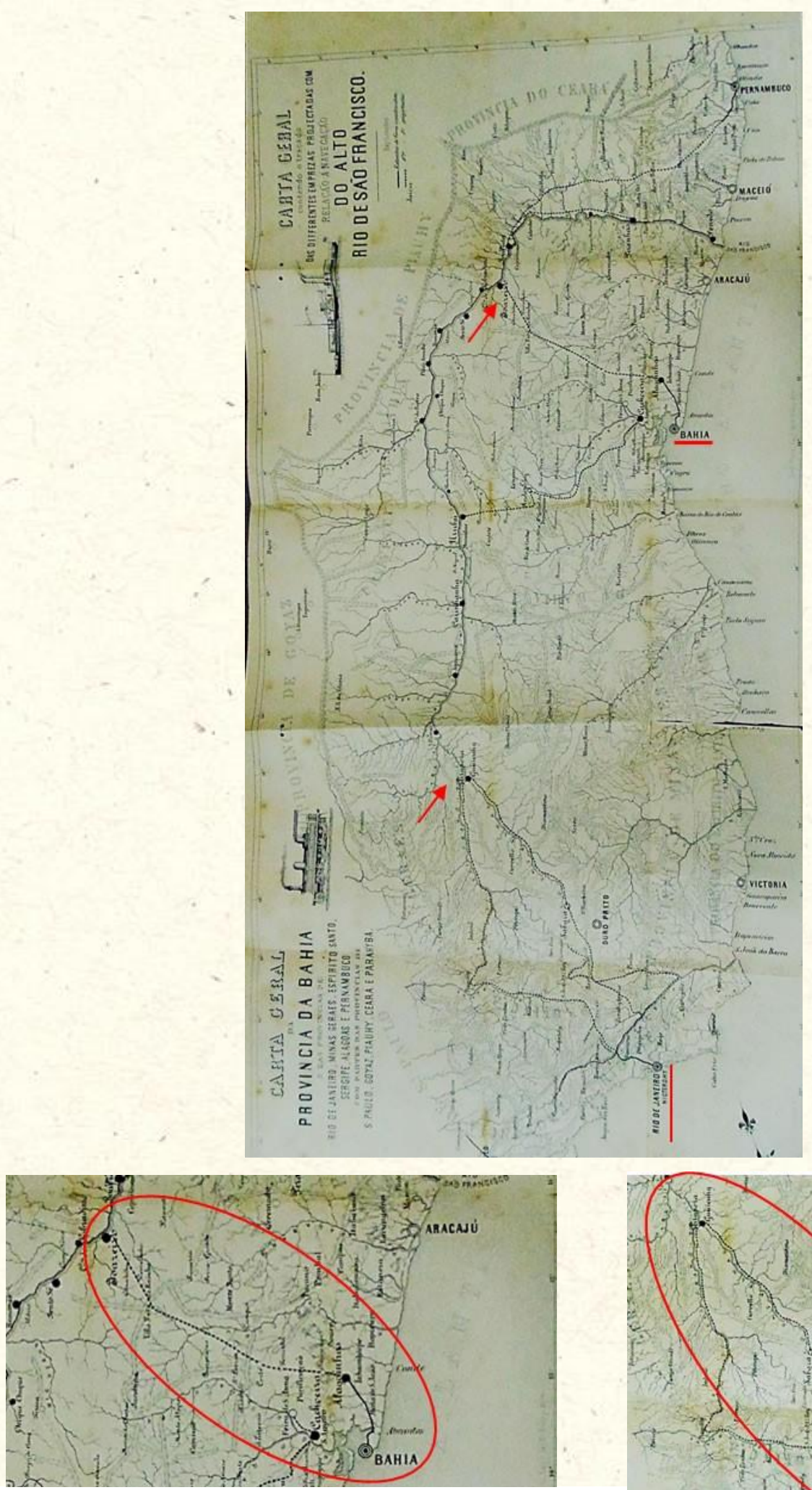

Imagem 3A

Imagem 3B

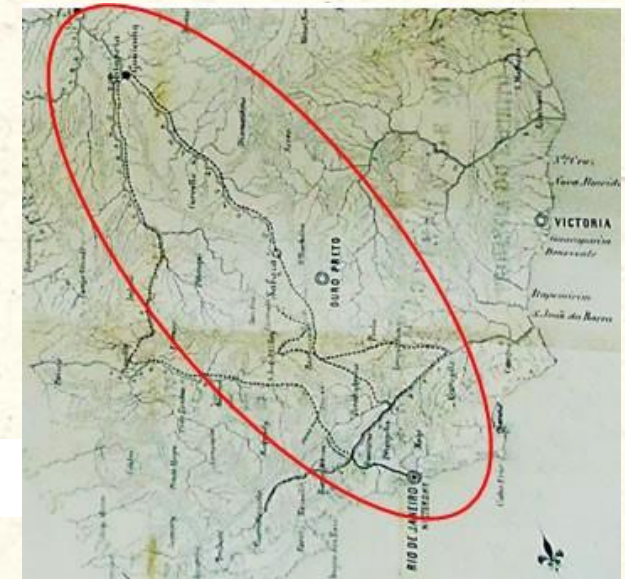

Imagem 3 - BNRJ. Carta Geral da Província da Bahia e das Províncias de Rio de Janeiro, Minas Geraes, Espírito Santo, Sergipe, Alagoas e Pernambuco com partes das Províncias de S. Paulo, Goyaz, Piauhy, Ceará e Parahyba. Carta Geral contendo o traçado das differentes emprezas projectadas com relação á navegação do Alto rio de São Francisco. [s. I.: s. n., s. d.]. In: Wilson, Hugh. Relatorio ... sobre 0 Rio São Francisco e os diversos projectos para ligar a navegação do alto rio com algum porto do littoral por Hugh Wilson, eng enheiro civil. Bahia: Typographia de J. G. Tourinho, 1870. 
Enquanto a estrada de ferro baiana aparecia no mapa como um caminho formado por linhas retas e em direção ao ponto máximo de navegação, que seria supostamente Juazeiro (ver imagem 3A), a D. Pedro II seria marcada por um percurso bem mais longo e bastante sinuoso (ver imagem 3B). Na visão de Wilson, a decisão sobre qual o melhor caminho não seria algo arbitrário, mas estaria demonstrada pela própria natureza. Bastaria "olhar para a carta topográfica [...] para se convencer que o porto do Rio de Janeiro não é porto legítimo por onde devam ser transportadas as riquezas do vale do Rio S. Francisco". Com o mapa a sua vista, a melhor alternativa para interligar aquele vale ao litoral era clara: "Em proximidade ao alto Rio S. Francisco é inegável que o porto da Bahia é o mais favoravelmente situado". 49

Já para 0 engenheiro André Rebouças, ${ }^{50}$ a capital imperial não detinha condições naturais de ser 0 centro convergente do Brasil. De acordo com ele, e em clara contraposição a leituras como a de Whitaker, as serras do Mar e da Mantiqueira, existentes entre a Corte e o São Francisco, levavam "para bem Ionge do porto do Rio de Janeiro o único rio importante das suas circunvizinhanças". Além disso, a própria direção da correnteza fluvial indicava outro caminho para os fluxos pelo vale. Para Rebouças, esse caminho era, sem dúvida, aquele em favor da Bahia. Daí sua ênfase na ideia de que "não se pode inverter as leis naturais; as águas correm para o mar: não é possível fazê-las retroceder para o cume das montanhas". A ocorrência de serras e a própria direção das correntes fluviais do São Francisco seriam provas, explícitas em mapas, de que a capital baiana era o destino natural das circulações em torno daquele vale do Brasil central. "Dê-se, pois, à Bahia o que é da Bahia", concluiu 0 engenheiro baian.$^{51}$

Outra experiência também bastante sintomática dessas apropriações de traços da natureza de modo articulado a planos políticos envolveu a proposta de abertura de canal desde o São Francisco ao rio Jaguaribe, na província do Ceará. Ao contrário das propostas ferroviárias da Bahia e da Corte, tal proposta de canalização não teve suas obras iniciadas durante 0 século XIX. No entanto, isso não significa que as discussões e reivindicações em torno desse projeto hidráulico tenham sido retraídas ou de pouca importância naqueles anos.

Em meio à guerra cartográfica, um dos principais artifícios, senão o principal, para tentar legitimar o projeto de canalização foi o mapa elaborado por Marcos Macedo ${ }^{52}$ com base em seus estudos exploratórios no rio São Francisco iniciados em 1839. Litografado em $1848,{ }^{53} 0$ desenho englobava a região entre 0 São Francisco e 0 sul da província do Ceará (ver imagem 4) e seria o meio de inscrever o canal no espaço imperial e provar a viabilidade de sua execução.

Em artigo publicado em 1855, Macedo aprofundou vários aspectos de seu mapa, explicitando nuances de como ele leu a natureza da maneira mais conveniente possível ao canal do São Francisco ao Ceará. Para 0 bacharel, "todos os geógrafos" de então estavam equivocados em crer "que a serra do Araripe faz parte da cordilheira Borborema", constituindo uma barreira contígua em toda a extremidade sul do Ceará até a província vizinha da Paraíba. Como esse era um dos principais pontos levantados pelos críticos do canal como motivo para sua inviabilidade, o objetivo de Macedo era provar o contrário, ou seja, a existência de passagens naquela região, de modo a possibilitar 0 "encanamento do rio de S. Francisco para 0 Ceará" ${ }^{54}$

\footnotetext{
${ }^{49}$ Relatorio apresentado ao excelentissimo Sr. Barão de S. Lourenço Presidente da Provincia e ao Corpo Commercial da Bahia sobre o Rio São Francisco e os diversos projectos para ligar a navegação do alto rio com algum porto do littoral por Hugh Wilson, engenheiro civil (Bahia: Typographia de J. G. Tourinho, 1870 ), $15,17$.

${ }^{50}$ André Pinto Rebouças (1838-1898) nasceu na capital da província da Bahia. Obteve o título de bacharel em Ciências Físicas e Matemáticas, atuando como engenheiro civil. Atuou em diversas comissões técnicas do governo imperial.

${ }^{51}$ Rebouças, André. Garantia de Juros. estudos para sua applicação ás emprezas de utilidade publica no Brasil (Rio de Janeiro, Typographia Nacional, 1874$)$, $207-217$.

${ }^{52}$ Marcos Antonio de Macedo (1808-1872) nasceu em Jaicós, no Piauí. Sua família, no entanto, vivia na comarca do Crato, no Ceará. Ele se bacharelou em Ciências Jurídicas e Sociais e foi estudioso de ciências naturais. Foi juiz, Deputado Provincial no Ceará, Presidente da Província e Deputado Geral pelo Piauí.

${ }^{53}$ Não consta nos dados do mapa a data de sua publicação. Todavia, adoto aqui a data da 1848 com base nos escritos de Marcos Antonio de Macedo e nos estudos de Br. de Studart. Ver: Macedo, Marcos Antonio de. A canalisação do Rio S. Francisco ao Ceará. Um inédito de Marcos Antonio de Macedo. Revista da Academia Cearense. (Tomo II. Fortaleza, 1897), 202; Studart, Guilherme. Geographia do Ceará. Revista Trimensal do Instituto do Ceará. (t. XXXVII. Fortaleza: Typographia Minerva, 1923), 360361.

${ }^{54}$ Jornal 0 Cearense, Fortaleza. n. 836. 5 de junho de 1855. p. 2-3; Trabalhos da Sociedade Vellosiana. In: Jornal O Guanabara. Rio de Janeiro. 1855. ed. 002. Disponíveis em: <http://bndigital.bn.br/hemeroteca-digital/>. Acesso em: 18 set. 2014.
} 


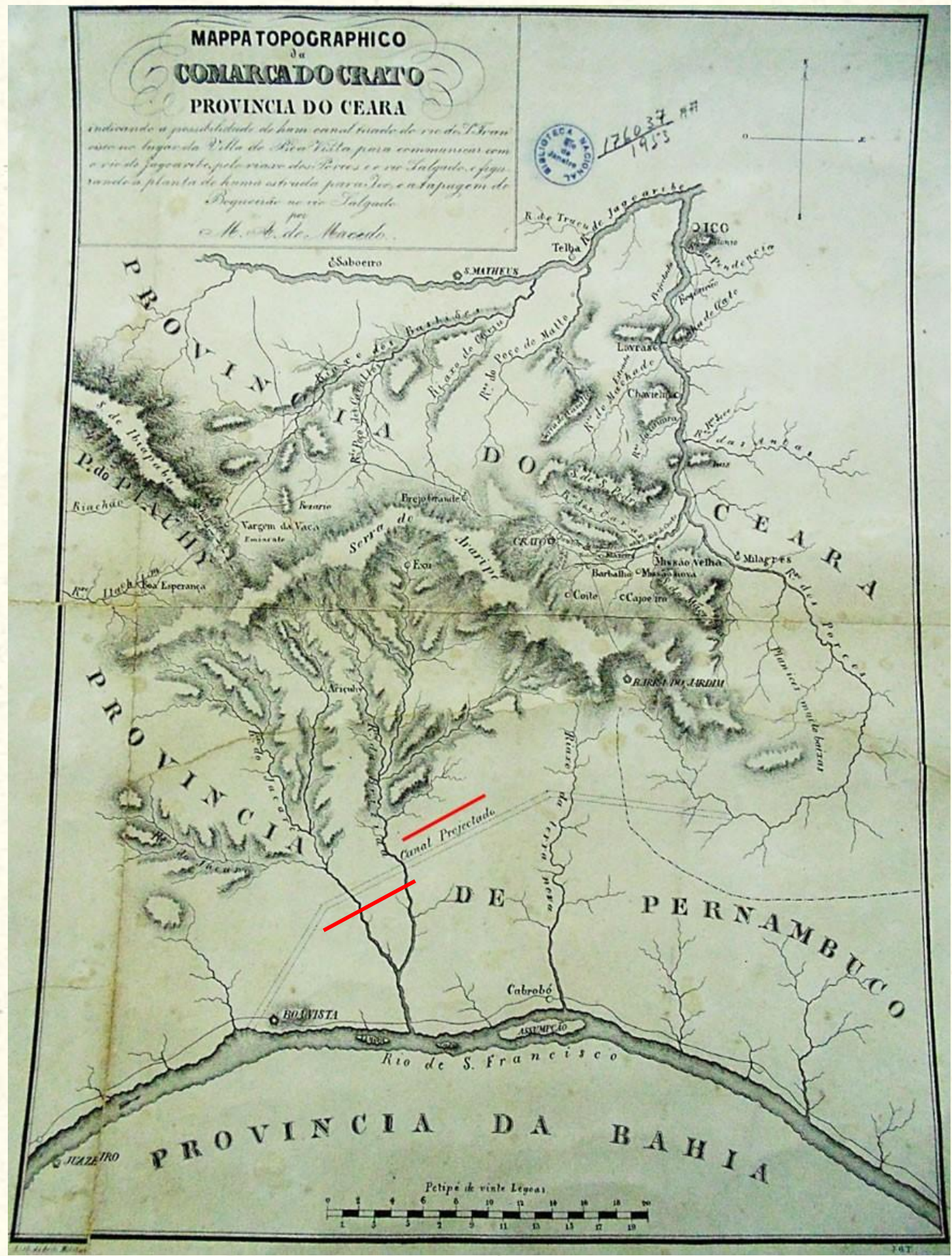

Imagem 4 - BNRJ. Mappa topographico da comarca do Crato provincia do Ceará indicando a possibilidade de hum canal tirado do rio de S. Francisco no lugar da villa de Boa Vista para comunicar com o rio Jagoaribe, pelo riaxo dos Porcos e o rio Salgado e figurando a planta de huma estrada para Ico, e a tapagem do Boqueirão no rio Salgado por M. A. de Macedo. Rio de Janeiro: Lithographia Archivo Militar, [s. d.]. 1 mapa. $33 \times 24 \mathrm{~cm}$.

Todavia, menos de dois anos antes, em¹853, Macedo garantiu não haver "dúvida que a Serra do Araripe faz parte do encadeamento da Borborema, porém é interceptada desde a Villa do Jardim até onde principia o grupo de montes que se prendem àquela cadeia formando uma baixada de mais de 10 léguas". ${ }^{55}$ Isto é, mesmo após a execução de estudos exploratórios e da litografia do mapa em 1848, o jurista não estava convicto quanto aos traços do Araripe. A definição se o planalto pertencia ou não ao planalto da Borborema permanecia ainda algo vago.

${ }^{55}$ Macedo, Marcos Antonio de. A canalisação do Rio S. Francisco aō Ceará. Um inédito de Marcos Antonio de Macedo. Revista da Academia Cearense (Tomo II. Fortaleza, 1897), 202-203 
A certeza de Macedo era a de que havia terrenos rebaixados nas cercanias da vila do Jardim, condição imprescindível ao projeto de canalização. E ele buscou tornar isso o mais evidente possível no mapa, a arma para atestar a veracidade de suas leituras da natureza. Para sanar qualquer dúvida, Macedo decidiu não apenas representar graficamente o rebaixamento, senão também escrever "planícies muito baixas" na parte relativa à área entre Jardim e o riacho dos Porcos (ver imagem 4A).

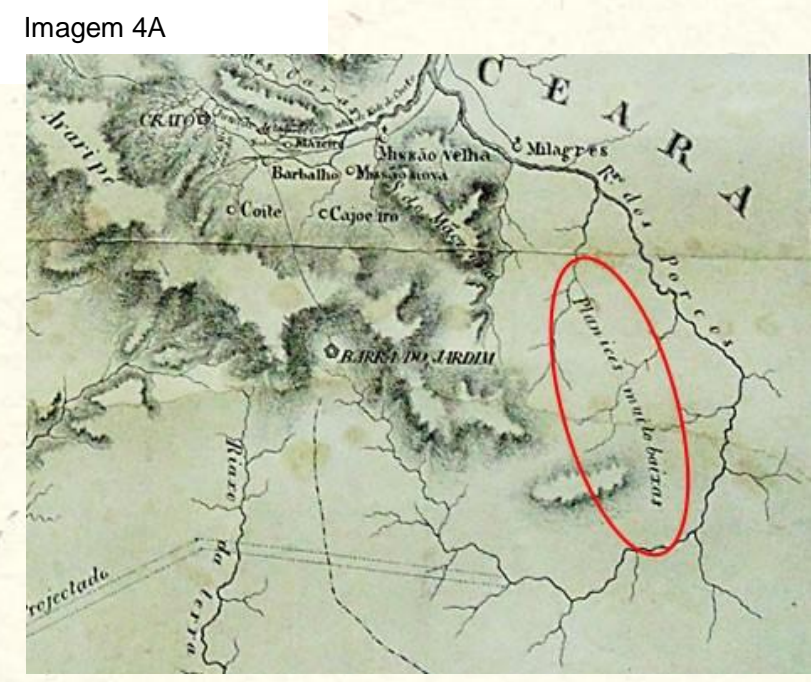

Ante 0 desafio de desenhar em um mapa a cadeia de terrenos elevados de modo propício à obra do canal, Macedo admitiu a necessidade de fazer escolhas sobre o que deveria constar ou não em sua carta geográfica. Ao omitir várias "montanhas", o jurista argumentou que "no mapa não vem figurada nem uma destas serrotas por serem de pouca importância nem de muita elevação". ${ }^{56}$ Longe de ser uma representação neutra do território, 0 desenho buscou construir a imagem da região entre o São Francisco e o Ceará como um campo livre de obstáculos para receber as águas do canal.

Nesse sentido, Macedo também se empenhou em provar a ocorrência de condições adequadas à navegação na área representada. Ele projetou em sua planta um caminho sem estorvos à navegabilidade desde Juazeiro até pouco a jusante do ponto de abertura do canal, nas cercanias de Boa Vista (ver imagem 4B). Ou seja, os obstáculos dignos de constarem no mapa ocorreriam somente após o local de onde partiria o canal e estariam demonstrados por meio do desenho de três ilhas.

${ }^{56}$ Macedo, Marcos Antonio de. A canalisação do Rio S. Francisco aō Ceará. Um inédito de Marcos Antonio de Macedo. Revista da Academia Cearense (Tomo II. Fortaleza, 1897), 203 


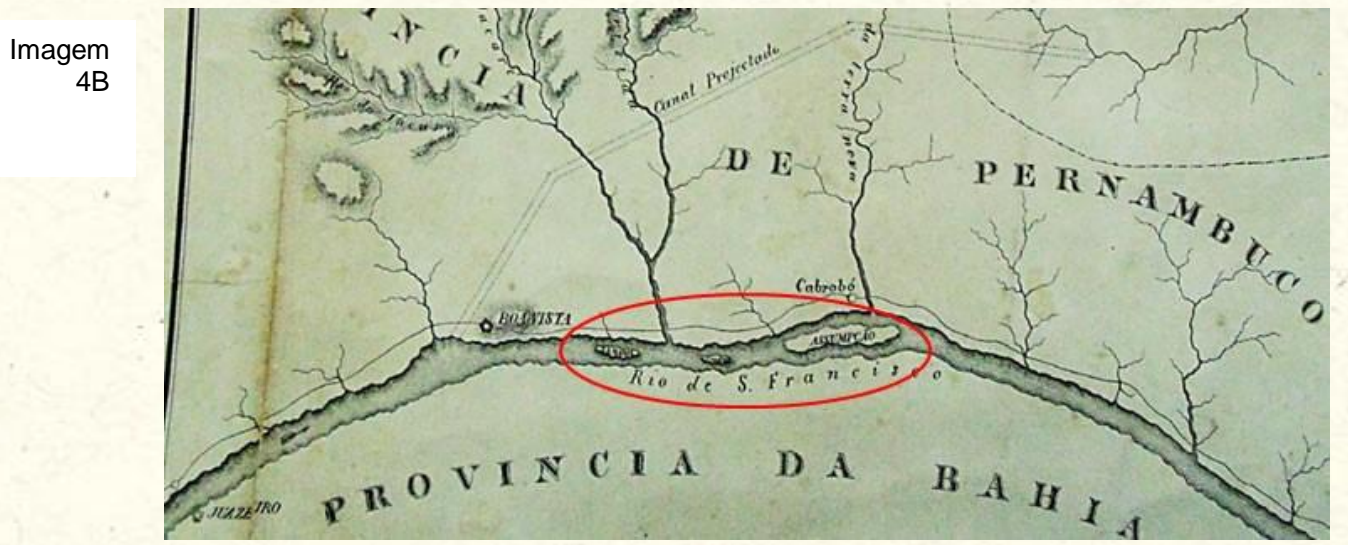

Contudo, estudiosos como Fernando Halfeld relataram dificuldades existentes no trecho dito como limpo por Macedo. Para aquele engenheiro, "da vila do Juazeiro, 24 léguas para baixo até a da Boa Vista, além de existir nesta extensão a cáchoeira do Genipapo, também se encontra grande número de pedras dispersas no leito do rio" ${ }^{57}$ Porém, para Macedo, a cartografia deveria mostrar a obra hidráulica como perfeitamente ajustada aos traços da natureza, possibilitando a navegação do São Francisco até o ponto máximo onde não haveria embaraços. 0 rio que fazia sentido para Macedo só possuiria adversidades após o trecho do canal. Num caminho curto e direto, formado por três linhas retas, o encanamento ligaria o São Francisco ao Jaguaribe seguindo o padrão moderno de caminhos os mais regulares e diretos possíveis (ver imagem 4).

Naqueles conflitos pelo São Francisco, os mapas funcionaram como meio importante para a construção da realidade de acordo não só com os interesses de grupos sociais específicos, seus aparatos técnicos e suas relações de poder, mas também com a materialidade do ambiente. Nas três projeções cartográficas aqui analisadas, os mais diferentes sujeitos leram os traços do rio da forma que lhes pareceu mais oportuna e recorreram aos mapas no sentido de afirmar suas respectivas apropriações da natureza. ${ }^{58}$

\section{Conclusão}

Inscrever o mundo natural em mapas se faz, então, num enlace situado historicamente entre sociedade e natureza. Como expressão das relações entre esses elementos, a cartografia permite 0 contato com noções sobre 0 ambiente de determinado período e espaço e, ao mesmo tempo, com os aspectos materiais da natureza também situada historicamente. Imersas em tramas de natureza e poder, as documentações cartográficas evidenciam como o meio físico é apropriado sob os mais variados prismas em função tanto de dinâmicas sociais quanto de traços do ambiente.

0 uso de plantas geográficas nas disputas pelo controle do rio São Francisco em meados do século XIX foi bastante característico nesse sentido. Numa autêntica batalha de mapas, cada grupo enxergou aquele vale fluvial e seus traços peculiares de acordo com seus projetos de poder. As plantas geográficas foram justamente a representação dessas várias leituras do rio, além de um artifício para tentar afirmar certas visões do território como as verdadeiras e alguns projetos como os melhores. Ao partir do pressuposto do meio físico não como mera superfície estática a funcionar como palco das ações humanas, mas como sociedade e natureza se fazem em conjunto, torna-se possível perceber como. diferentes sujeitos buscaram construir determinados arranjos territoriais, direcionando o fluxo do São Francisco do modo mais conveniente aos seus interesses.

Ao permitir a compreensão de como o meio físico é lido e faz sentido dos mais diferentes modos para grupos sociais diversos, os mapas mostram-se como fonte relevante para o campo da história ambiental. Repensar a cartografia, seja a do século XVI, XIX ou a baseada no GIS, para além de imagens ilustrativas, mas também como uma das principais expressões das relações entre seres humanos e natureza situadas historicamente pode

\footnotetext{
${ }^{57}$ Jornal Correio Mercantil. Rio de Janeiro. n. 200. 21 de julho de 1854. p. 1. Disponíveis em: <http://bndigital.bn.br/hemeroteca-digital/>. Acesso em: 8 out. 2014.

${ }^{58}$ Ver a este respeito: Oliveira, Gabriel Pereira de. O rio e o caminho natural. propostas de canais do São Francisco, aspectos físicos fluviais e dinâmicas políticas no Brasil Império (1846-1886). Dissertação. (Belo Horizonte: Programa de Pós-Graduação em História, 2015).
} 
contribuir bastante às análises do campo da história ambiental, num diálogo com a história da cartografia que pode ser bastante frutífero.

Agradecimentos: Facundo Rojas, Jaeckson, Jacqueline, Ana Carla, Antídio, Regina Horta, Eurípedes Funes e Júnia Furtado. 